\title{
Cardiology Journal: From Chopin's Revolutionary Etude toward the Argentinean Tango
}

\author{
Wojciech Zareba \\ Cardiology Division, University of Rochester Medical Center, Rochester, New York, USA
}

The past 7 years were truly revolutionary for Cardiology Journal. In 2006, when we started working with the journal, Folia Cardiologica was a Polish language journal serving the Polish cardiology community for 12 years as a venue to present scientific and educational content. We were asked to transform Folia Cardiologica into an international English language journal, which will gain a recognition and reputation worldwide. This task took us 7 years and we are glad to report that this mission was accomplished.

In 2007, the title was changed to Cardiology Journal and at that point the journal started operating fully in English. The title was changed in order to be indexed in Medline (due to a conflict with a prior title) and became a more attractive and easily recognizable title. In the same year, we were successful in obtaining approval of the US National Library of Medicine to index our journal in Index Medicus as a unique cardiology journal in the region.

In 2008, Cardiology Journal appeared in Medline which made possible for all articles published for the last 5 years to be accessed in Medline free of charge. This immediately resulted in more papers being submitted to the journal, and a large number of them from abroad.

In 2009, Thomson Reuters accepted our application to start the process of being evaluated regarding citations and Impact Factor.

In 2010, Cardiology Journal was becoming more and more popular among authors (348 submissions), and among readers who started citing our papers.

In 2012, our first Impact Factor of 1.309 was obtained, which places our journal in a category of well-regarded journals in the field. Importantly, only
$13 \%$ of these citations were self-citations which provided even further evidence for the high quality of papers published in Cardiology Journal.

Achieving such a good Impact Factor on our first evaluation translated into increasing popularity of the journal among authors. In 2012, there were 480 submissions, a steady increase in comparison to prior years (Fig. 1). This increasing submission rate faces a steady number of published papers (about 120-125 per year) resulting in an increasing rejection rate (Fig. 2). There were 425 papers rejected in 2012 (88\% of submitted papers). Such a high rejection rate contributes to increasing quality of submitted and accepted papers and gives good prospects for increasing citations. Figure 3 shows the current (as of December 31,2012) status of ci-

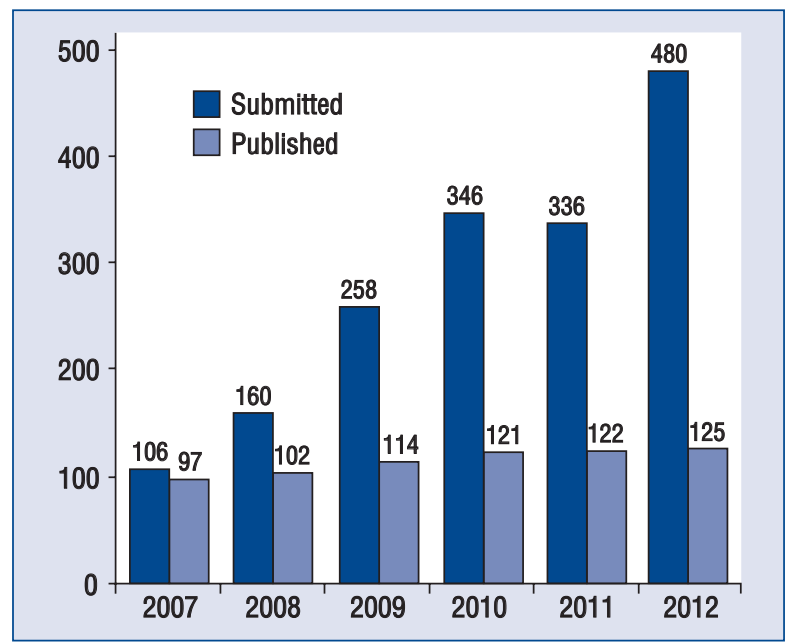

Figure 1. Cardiology Journal articles submitted and published.

Address for correspondence: Wojciech Zareba, MD, PhD, Heart Research, Cardiology Division, University of Rochester, Medical Center, Box 653, 601 Elmwood Ave., Rochester, NY 14642, USA, tel: 585275 5391, fax: 5852735283 ,

e-mail: wojciech_zareba@urmc.rochester.edu 


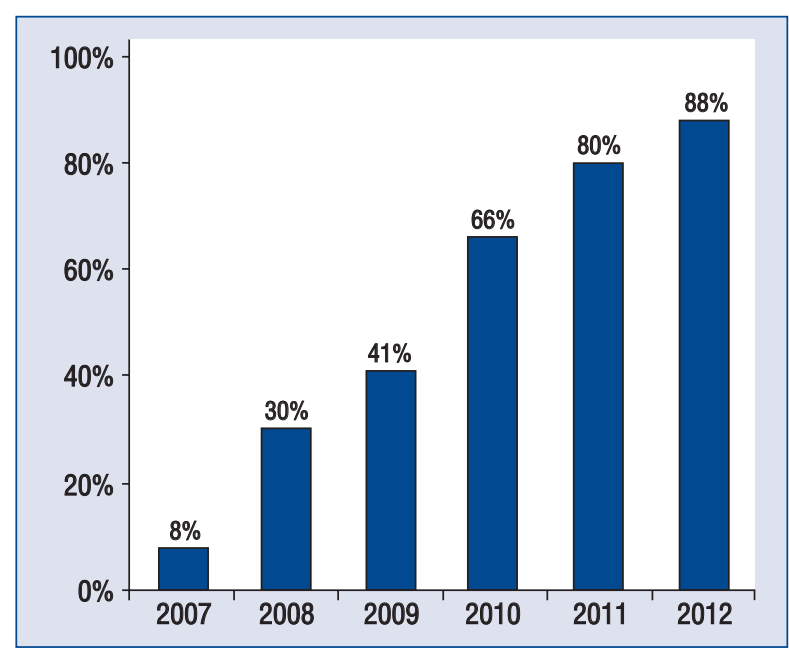

Figure 2. Cardiology Journal rejection rate.

tations of Cardiology Journal. We are pleased that it is steadily increasing!

We consider these past 7 years revolutionary for the journal, but revolutions are not possible without their leaders and supporters. There are numerous people who throughout the years believed in the journal and who were very supportive and contributed to writing, reviewing, advising, and supporting Cardiology Journal in various phases of its development. Below is a not all-inclusive list of key people whom we would like to thank (in alphabetic order):

Adrian Baranchuk, Kingston, Canada

Serge Barold, Tampa, USA

Andrzej Beresewicz, Warszawa, Poland

Jacek Bialkowski, Zabrze, Poland

Katarzyna Bieganowska, Warszawa, Poland

Zofia Bilinska, Warszawa, Poland

Yohai Birnbaum, Houston, USA

John Bisognano, Rochester, USA

Victor Olivera Carvalho, Mexico City, Mexico

Chris Cove, Rochester, USA

Iwona Cygankiewicz, Lodz, Poland

James Daubert, Durham, USA

Jozef Drzewoski, Lodz, Poland

Sergio Dubner, Buenos Aires, Argentina

Dariusz Dudek, Krakow, Poland

Marek Dziubinski, Warszawa, Poland

Nabil El-Sherif, New York, USA

Krzysztof Filipiak, Warszawa, Poland

Charles Francis, Rochester, USA

Jeffrey Goldberger, Chicago, USA

Irmina Gradus-Pizlo, Indianapolis, USA

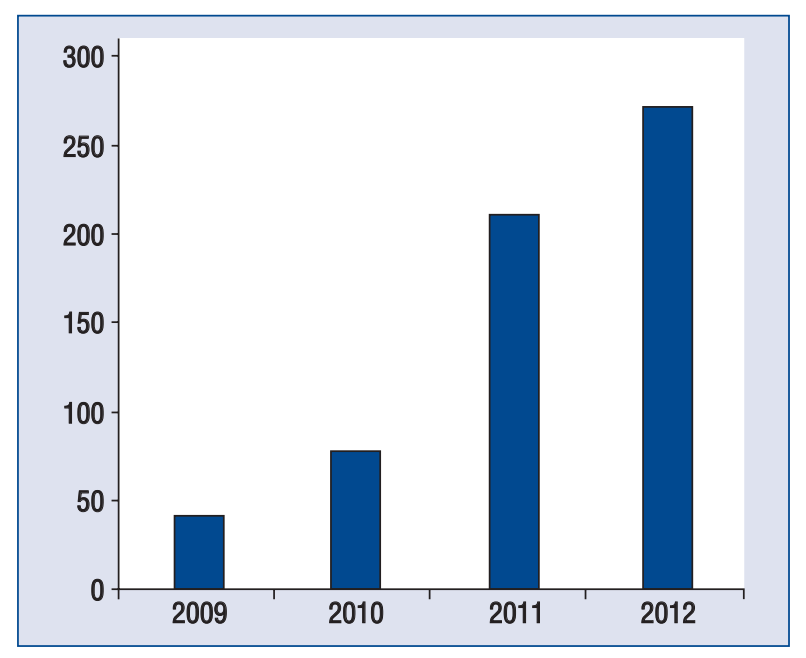

Figure 3. Estimated citations of papers from Cardiology Journal.

Blair Grubb, Toledo, USA

Mark Haigney, Bethesda, USA

Ziyad Hijazi, Chicago, USA

Piotr Hoffman, Warszawa, Poland

Wlodzimierz Kargul, Katowice, Poland

Jaroslaw Kasprzak, Lodz, Poland

Helmut Klein, Munich, Germany

Paul Kligfield, New York, USA

Jerzy Korewicki, Warszawa, Poland

Jacek Kubica, Bydgoszcz, Poland

Wlodzimierz Kuroczynski, Meinz, Germany

Andrzej Kutarski, Lublin, Poland

Andrzej Lekston, Zabrze, Poland

Fred Ling, Rochester, USA

Suave Lobodzinski, Long Beach, USA

Krystyna Loboz-Grudzien, Wroclaw, Poland

Ewa Malecka, Krakow, Poland

Ewa Michalak, Warszawa, Poland

David Mortara, Milwaukee, USA

Craig Narins, Rochester, NY

Jadwiga Nessler, Krakow, Poland

Joanna Niezgoda, Gdansk, Poland

Brian Olshansky, Iowa City, USA

Ali Oto, Ankara, Turkey

Ewa Piotrowicz, Warszawa, Poland

Ryszard Piotrowicz, Warszawa, Poland

Lech Polonski, Zabrze, Poland

Janusz Popaszkiewicz, Gdansk, Poland

Andres Perez Riera, Sao Paulo, Brazil

Thomas Rocco, Rochester, USA

John Scherer, Pittsburgh, USA

Maciej Sosnowski, Katowice, Poland

Shlomo Stern, Tel Aviv, Israel

Lukasz Stolarczyk, Gdansk, Poland 
Adam Sukiennik, Bydgoszcz, Poland

Wieslawa Tracz, Krakow, Poland

Olga Trojnarska, Poznan, Poland

Maria Trusz-Gluza, Katowice, Poland

Gioia Turitto, New York, USA

Adam Witkowski, Warszawa, Poland

Beata Wozakowska-Kaplon, Kielce, Poland

Krzysztof Wranicz, Lodz, Poland

Grazyna Zareba, Rochester, USA

Karolina Zareba, Pittsburgh, USA

Marzenna Zielinska, Lodz, Poland

Special recognition should be given to Dr. Janusz Popaszkiewicz and Dr. Lukasz Stolarczyk, who have supported and continue to support the journal as a hobby and consider it as a contribution to their beloved field of cardiology. They have always been thriving to make the journal better: first during the 12 years of its existence as Folia Cardiologica and now during the last 7 years as Cardiology Journal. The quality of editorial work by Via Medica, the publisher from Gdansk, Poland, is truly outstanding and not many journals around the world could compete with the quality of our publishing house. Among many amazing team members of Via Medica, Mrs. Joanna Niezgoda, who has been serving as Publishing Editor for Cardiology Journal, deserves special thanks and recognition. Her professional attitude, attention to details, promptness in response, and excellent expertise were essential for success of the Cardiology Journal revolutionary path to success.
Last but not least, a special thanks and words of gratitude go to my wife, Grazyna Zareba, who has served as Managing Editor for the journal for the last 7 years. She has many talents: in addition to her career in toxicology and public health, her excellent organizational skills and managing the journal were crucial to the success of Cardiology Journal. Without her daily devotion Cardiology Journal would not be where we are today!

Since the mission has been accomplished, it is time for the Journal to start a new chapter and become even more international! Let me therefore introduce Dr. Sergio Dubner from Buenos Aires, Argentina, as the new Editor-in-Chief of Cardiology Journal starting in 2013. Dr. Sergio Dubner is a very good friend and colleague who will be leading Cardiology Journal into the new era with even further involvement of internet-based tools. Dr. Dubner is a very-well recognized leader in the field of cardiac arrhythmias, but more importantly he is truly an excellent organizer. $\mathrm{He}$ is the past President of the International Society for Holter and Noninvasive Electrocardiology (ISHNE) and has served in leading roles in a number of South American Societies. For the last 10 years he has been serving as the Director of Internet WebBased ISHNE Symposia reaching 20,000 cardiologists in over 40 countries with his internet-based educational programs (www.ishne.org). In the rhythm and spirit of the Argentinean tango his leadership will give new wind to Cardiology Journal for years to come.

It was a pleasure to work with all of you and to serve the cardiology community at large.

Happy New Year! 